\title{
Modeling of State and Thermodynamic Cycle Properties of HFO-1234yf Using a Cubic Equation of State
}

\author{
Moisés A. Marcelino Neto \\ moises@polo.ufsc.br \\ Department of Mechanical Engineering \\ Federal University of Santa Catarina \\ 88040900 Florianópolis, SC, Brazil \\ Jader R. Barbosa, Jr. \\ jrb@polo.ufsc.br \\ Department of Mechanical Engineering \\ Federal University of Santa Catarina \\ 88040900 Florianópolis, SC, Brazil
}

Thermodynamic property data including specific enthalpy, specific entropy and specific volume were generated for the new refrigerant HFO-1234yf (2,3,3,3-tetrafluoroprop-1-ene) using the well-known Peng and Robinson cubic equation of state. A general approach applicable to any fluid based on the concept of departure functions has been applied. Data for saturated vapor pressure, saturated liquid density, ideal gas heat capacity at constant pressure and critical properties were obtained from the open literature. The predictive capability of the proposed calculation methodology has been validated with thermodynamic property data for HFC-134a (1,1,1,2-tetrafluoroethane), showing average deviations lower than $0.6 \%$. A thermodynamic analysis of the new refrigerant in the light of thermodynamic properties of an idealized cycle was carried out so as to measure its performance with respect to that HFC-134a under the same evaporating and condensing pressure conditions. Keywords: R-1234yf, thermodynamic property, thermodynamic cycle, equation of state

\section{Introduction}

Recently, a new synthetic chemical, HFO-1234yf (2,3,3,3tetrafluoroprop-1-ene), was identified as a potential substitute for existing refrigerants in mechanical vapor compression refrigeration systems. It has a Global Warming Potential (GWP) of 4, zero Ozone Depletion Potential (ODP) and vapor pressure and other properties similar to those of HFC-134a (1,1,1,2-tetrafluoroethane).

Despite the growing interest in applications involving this new refrigerant, there is still a limited amount of thermodynamic and cycle data in the open literature. Minor and Spatz (2008) presented the main characteristics of HFO-1234yf associated with its toxicity, flammability, life cycle climate performance, materials compatibility and thermodynamic cycle performance. They concluded that it has excellent potential as a new low global warming refrigerant for automotive air conditioning and stationary applications. Leck (2009) presented data on the saturated vapor pressure, saturated liquid density and ideal gas heat capacity. He developed a Martin-Hou equation of state for calculating the thermodynamic properties and evaluated the stability and compatibility of HFO-1234yf with lubricants and other materials. A succinct evaluation of the performance of HFO-1234yf as a working fluid in refrigeration applications was also presented. Hulse et al. (2009) evaluated experimentally the critical temperature, saturated vapor pressure, saturated liquid density, ideal gas heat capacity at constant pressure and compressed liquid viscosity of HFO-1234yf. A corresponding states equation was obtained from a regression of the experimental data, which also enabled a concise performance analysis of HFO-1234yf for mobile air conditioning applications. Tanaka and Higashi (2009) presented experimental data on critical properties, vapor pressure and surface tension of HFO-1234yf. The acentric factor was calculated based on the proposed vapor pressure correlation. Based on the critical parameters and acentric factor, saturated vapor and liquid densities were estimated by the Peng and Robinson (1976) equation of state and the Hankinson and Thomson (1979) correlation, respectively. The heat of vaporization was calculated from the Clausius-Clapeyron equation. Brown et al. (2009) estimated the properties of eight fluorinated propene isomers (including HFO-1234yf) using an approximate method that involves the Peng and Robinson (1976) equation of state and standard methods (Poling et al., 2000) for calculating the ideal gas specific

Paper accepted May, 2010. Technical Editor: José A. dos Reis Parise heat capacity at constant pressure, the acentric factor and the critical point properties (temperature, pressure and density). The HFO1234yf saturation data were compared to those provided by Minor and Spatz (2008). Brasz (2009) performed a comparative evaluation of the use of HFO-1234yf as a refrigerant in systems operating with variable speed centrifugal compressors between evaporating and condensing temperatures of $5.56^{\circ} \mathrm{C}$ and $35.56^{\circ} \mathrm{C}$, respectively.

The objective of this work is to present a calculation procedure of intensive thermodynamic properties (enthalpy, entropy and volume) of HFO-1234yf using the Peng-Robinson (1976) equation of state and a general approach based on the concept of departure functions. Both saturated liquid and vapor, subcooled liquid and superheated vapor regions have been considered. The data are of particular importance in the design of refrigeration systems and in comparative performance analyses of HFO-1234yf in existing applications. To this end, an evaluation of thermodynamic cycle properties such as the specific refrigerating effect, the volumic refrigerating effect, the specific work of isentropic compression, the volumic work of isentropic compression, the compressor discharge temperature and the coefficient of performance (Gosney, 1982) has been performed in order to contrast the performances of HFO$1234 \mathrm{yf}$ and HFC-134a in an idealized vapor compression refrigeration cycle.

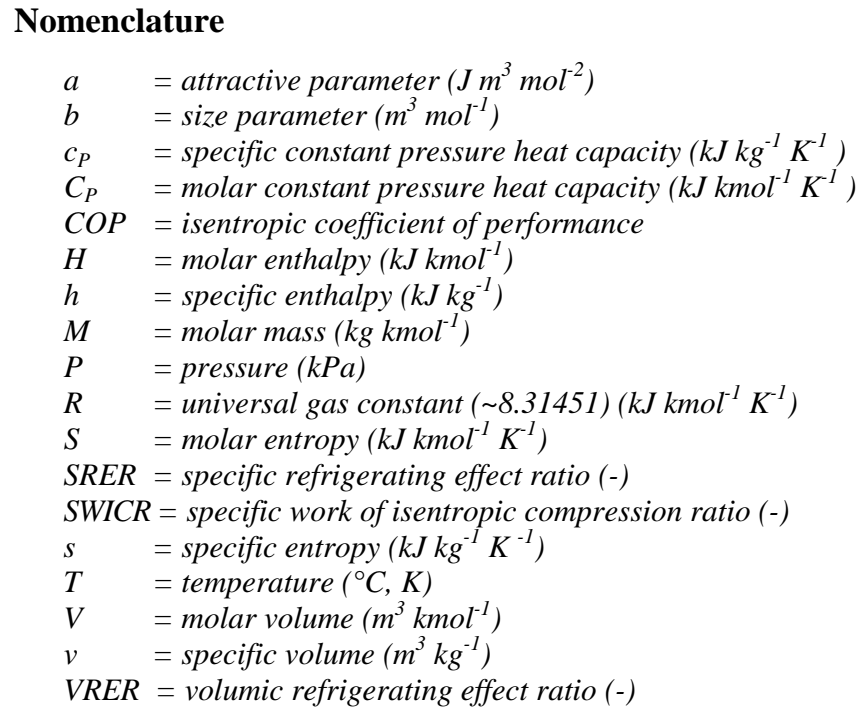




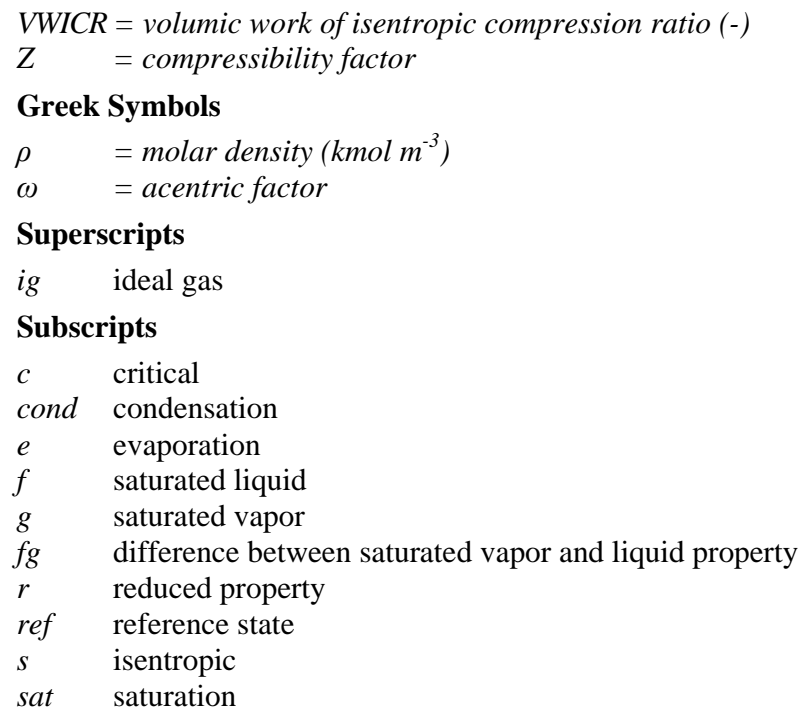

\section{Calculation Methodology}

An equation of state is a relationship between state variables used to describe the state of matter of pure fluids and their mixtures under a given set of physical conditions. In order to utilize such an equation to estimate the thermodynamic properties of a substance at a given state (e.g., enthalpy and entropy) with the minimum amount of experimental input data, one should combine it with the wellknown Maxwell relations and other fundamental relationships involving the system properties.

In terms of the compressibility factor, the Peng and Robinson (1976) equation of state can be written as:

$$
Z=\frac{1}{(1-b \rho)}-\frac{a}{b R T} \frac{b \rho}{1+2 b \rho-b^{2} \rho^{2}}
$$

where,

$$
\begin{aligned}
a & \equiv 0.45723553 \frac{R^{2} T_{c}{ }^{2}}{P_{c}}\left[\begin{array}{c}
1+(0.37464+1.54226 \omega- \\
\left.0.26993 \omega^{2}\right)\left(1-\sqrt{T_{r}}\right)
\end{array}\right]^{2} \\
b & \equiv 0.07779607 \frac{R T_{c}}{P_{c}}
\end{aligned}
$$

The difference between the real fluid property and the ideal gas property of a given substance at fixed $T, P$ is known as a departure function. Relationships for the molar enthalpy and entropy departure functions to be used in conjunction with the Peng and Robinson (1976) equation of state at fixed T,P are given by (Elliot and Lira, 1999):

$$
\begin{aligned}
& \frac{\left(H-H^{i g}\right)_{T, P}}{R T}=\int_{0}^{\rho}-T\left[\frac{\partial Z}{\partial T}\right]_{\rho} \frac{d \rho}{\rho}+Z-1 \\
& \frac{\left(S-S^{i g}\right)_{T, P}}{R}=\int_{0}^{\rho}\left[-T\left[\frac{\partial Z}{\partial T}\right]-(Z-1)\right]_{\rho} \frac{d \rho}{\rho}+\ln Z
\end{aligned}
$$

Lastly, for a real fluid with respect to a reference state, the values of enthalpy and entropy can be calculated from (Elliot and Lira, 1999):

$$
\begin{aligned}
& H=\left(H-H^{i g}\right)_{T, P}+\int_{T_{r e f}}^{T} C_{P}^{i g} d T-\left(H-H^{i g}\right)_{r e f}+H_{r e f} \\
& S=\left(S-S^{i g}\right)_{T, P}+\int_{T_{r e f}}^{T} \frac{C_{P}^{i g}}{T} d T-R \ln \frac{P}{P_{r e f}}-\left(S-S^{i g}\right)_{r e f}+S_{r e f}
\end{aligned}
$$

where the subscripts $T, P$ refer to the departure function and ref stands for the reference state. The reference state adopted here is that of the International Institute of Refrigeration (IIR) which specifies values of specific enthalpy and specific entropy of $200 \mathrm{~kJ}$ $\mathrm{kg}^{-1}$ and $1.0 \mathrm{~kJ} \mathrm{~kg}^{-1} \mathrm{~K}^{-1}$ for the saturated liquid at $0^{\circ} \mathrm{C}(273.15 \mathrm{~K})$, respectively. The reference enthalpy and entropy for saturated vapor were calculated using the Clausius-Clapeyron equation as follows (Elliot and Lira, 1999):

$$
\begin{aligned}
& H_{g}=H_{f}+T \frac{d P_{\text {sat }}}{d T}\left(V_{g}-V_{f}\right) \\
& S_{g}=S_{f}+\frac{\left(H_{g}-H_{f}\right)}{T}
\end{aligned}
$$

where the saturated vapor molar volume was calculated with the Peng and Robinson (1976) equation of state. The experimental data required in the model (saturated vapor pressure, saturated liquid density, critical properties and ideal gas heat capacity at constant pressure) were obtained from the work of Leck (2009) and are summarized in the Appendix.

Specific enthalpy, entropy and volume data for HFO-1234yf were generated along the saturated liquid and vapor lines, as well in the compressed liquid and superheated vapor regions. In order to validate the predictive capability of the calculation procedure, data were also generated for saturated HFC-134a and compared with those given by a standard database generated via the Tillner-Roth and Baehr (1994) equation of state (Lemmon et al., 2007). The average/maximum deviations associated with these predictions are shown in Table 1.

The saturation properties of HFO-1234yf calculated via the present approach were also compared with the predictions of the Martin-Hou equation of state proposed by Leck (2009). The average/maximum deviations associated with these predictions are shown in Table 2.

The calculated thermodynamic properties of HFO-1234yf were used in a performance evaluation of an idealized vapor-compression refrigeration cycle with an internal heat exchanger (Stoecker and Jones, 1982). In this idealized cycle, the vapor exits the evaporator with a superheat of $5^{\circ} \mathrm{C}(1)$ and is admitted into the compressor at a temperature $T_{1},>T_{1}$ which depends on the effectiveness $\varepsilon$ of the internal heat exchanger. The vapor enters the compressor at the evaporating pressure (1'), undergoes an isentropic compression up to the condensing pressure (2) and condenses at constant pressure, exiting the condenser as a saturated liquid (3). The refrigerant is subcooled in the internal heat exchanger (3'), undergoes an isenthalpic expansion down to the evaporating pressure (4) and finally evaporates at constant pressure.

The internal heat exchanger effectiveness is defined as the ratio of the actual heat transfer rate and the maximum heat transfer rate as follows:

$$
\varepsilon=\frac{h_{v}\left(p_{e}, T_{1^{\prime}}\right)-h_{v}\left(p_{e}, T_{1}\right)}{h_{v}\left(p_{e}, T_{3}\right)-h_{v}\left(p_{e}, T_{1}\right)}
$$


Table 1. Validation of calculation procedure for HFC-134a.

\begin{tabular}{ccc}
\hline Property at saturation & Average deviation [\%] & Maximum deviation [\%] \\
\hline Liquid enthalpy & -0.097 & -0.125 \\
\hline Vapor enthalpy & -0.007 & 0.059 \\
\hline Liquid entropy & -0.069 & -0.102 \\
\hline Vapor entropy & 0.016 & 0.053 \\
\hline Vapor specific volume & 0.6173 & 0.8633 \\
\hline
\end{tabular}

Table 2. Validation of calculation procedure for HFO-1234yf.

\begin{tabular}{ccc}
\hline Property at saturation & Average deviation [\%] & Maximum deviation [\%] \\
\hline Liquid enthalpy & -0.591 & -2.330 \\
\hline Vapor enthalpy & -0.982 & -1.382 \\
\hline Liquid entropy & 0.413 & 2.010 \\
\hline Vapor entropy & -0.783 & -1.054 \\
\hline Vapor specific volume & -2.026 & -2.272 \\
\hline
\end{tabular}

The cycle analysis is carried out in terms of the following parameters (Gosney, 1982): (i) the specific refrigerating effect $\left(h_{1^{-}}\right.$ $h_{4}$ ), (ii) the volumic refrigerating effect $\left(h_{1}-h_{4}\right) / v_{1}$, (iii) the specific work of isentropic compression $\left(h_{2}-h_{1} \text {, }\right)_{s}$, (iv) the volumic work of isentropic compression $\left(h_{2}-h_{1}\right)_{s} / v_{1}$, and (v) the isentropic coefficient of performance $\left(h_{1}-h_{4}\right) /\left(h_{2}-h_{1}\right)_{s}$.

\section{Results and Discussion}

Table 3 presents a sample of the saturated HFO-1234yf data. A more complete set of tables (including the superheated region) and a computer program in the EES platform (Klein, 2010) are available from the authors upon request. In the subcooled liquid region, as expected, the variation of the enthalpy as a function of pressure at constant temperature was insignificant (typically less than $1.1 \%$ ), except near the critical point. Figures 1 and 2 show the pressurespecific enthalpy $(P-h)$ diagrams for HFO-1234yf and HFC-134a, respectively. Lines of constant temperature and of constant entropy are shown together with the idealized refrigeration cycle between evaporating and condensing temperatures of $-23.3^{\circ} \mathrm{C}$ and $54.4^{\circ} \mathrm{C}$ (the so-called checkpoint condition) for both refrigerants. In the idealized cycles shown in these figures, the internal heat exchanger effectiveness has been set equal to unity in order to magnify the most relevant differences between the fluids. These differences will be explored next in the light of the thermodynamic cycle quantities.

Table 3. Properties of HFO-1234yf at Saturation Conditions.

\begin{tabular}{ccccccccc}
\hline $\begin{array}{c}T \\
\left({ }^{\circ} \mathrm{C}\right)\end{array}$ & $\begin{array}{c}P_{\text {sat }} \\
(\mathrm{kPa})\end{array}$ & $\begin{array}{c}v_{f} \\
\left(\mathrm{~m}^{3} / \mathrm{kg}\right)\end{array}$ & $\begin{array}{c}v_{g} \\
\left(\mathrm{~m}^{3} / \mathrm{kg}\right)\end{array}$ & $\begin{array}{c}h_{f} \\
(\mathrm{~kJ} / \mathrm{kg})\end{array}$ & $\begin{array}{c}h_{f g} \\
(\mathrm{~kJ} / \mathrm{kg})\end{array}$ & $\begin{array}{c}h_{g} \\
(\mathrm{~kJ} / \mathrm{kg})\end{array}$ & $\begin{array}{c}s_{f} \\
(\mathrm{~kJ} / \mathrm{kgK})\end{array}$ & $\begin{array}{c}s_{g} \\
(\mathrm{~kJ} / \mathrm{kgK})\end{array}$ \\
\hline-40 & 62.20 & 0.000776 & 0.266052 & 151.95 & 186.59 & 338.54 & 0.80044 & 1.61091 \\
\hline-30 & 98.50 & 0.000792 & 0.173161 & 163.42 & 181.98 & 345.40 & 0.85332 & 1.60725 \\
\hline-20 & 149.91 & 0.000809 & 0.116692 & 175.23 & 177.02 & 352.25 & 0.90399 & 1.60562 \\
\hline-10 & 220.32 & 0.000828 & 0.080992 & 187.41 & 171.64 & 359.05 & 0.95277 & 1.60558 \\
\hline 0 & 314.03 & 0.000849 & 0.057628 & 200.00 & 165.74 & 365.74 & 1.00000 & 1.60677 \\
\hline 10 & 435.64 & 0.000873 & 0.041861 & 213.04 & 159.22 & 372.26 & 1.04597 & 1.60881 \\
\hline 20 & 590.02 & 0.000899 & 0.030926 & 226.59 & 151.95 & 378.53 & 1.09100 & 1.61137 \\
\hline 30 & 782.30 & 0.000930 & 0.023152 & 240.71 & 143.76 & 384.47 & 1.13543 & 1.61409 \\
\hline 40 & 1017.86 & 0.000966 & 0.017497 & 255.53 & 134.43 & 389.97 & 1.17963 & 1.61656 \\
\hline 50 & 1302.35 & 0.001009 & 0.013294 & 271.19 & 123.66 & 394.85 & 1.22411 & 1.61829 \\
\hline 60 & 1641.91 & 0.001062 & 0.010100 & 287.95 & 110.93 & 398.88 & 1.26959 & 1.61859 \\
\hline 70 & 2043.48 & 0.001133 & 0.007611 & 306.26 & 95.37 & 401.63 & 1.31730 & 1.61631 \\
\hline 80 & 2515.77 & 0.001237 & 0.005598 & 327.10 & 75.09 & 402.19 & 1.36985 & 1.60906 \\
\hline 90 & 3072.84 & 0.001442 & 0.003805 & 353.98 & 43.43 & 397.41 & 1.43647 & 1.58849 \\
\hline
\end{tabular}




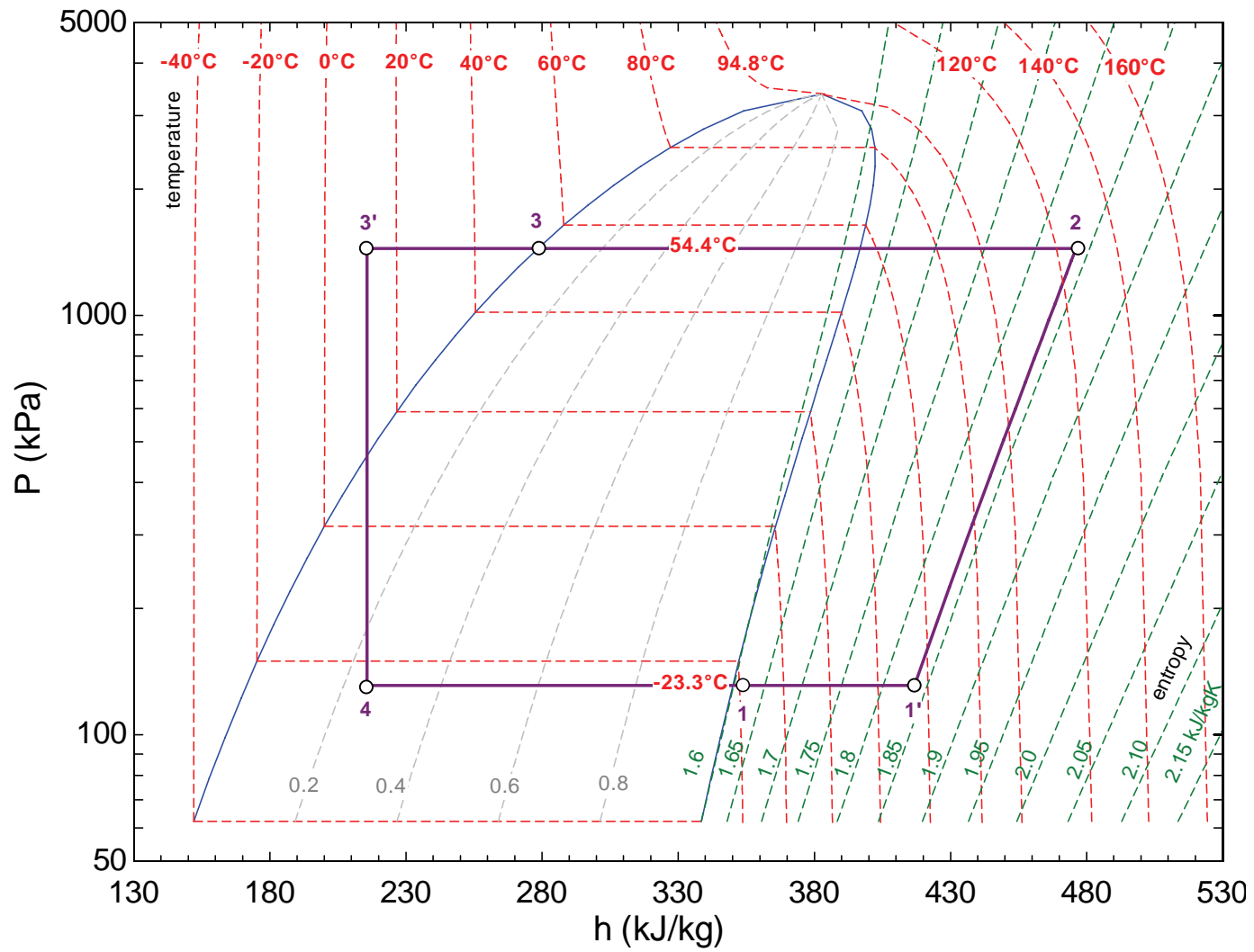

Figure 1. P-h diagram of HFO-1234yf with an idealized vapor compression cycle at the check-point condition. The effectiveness of the internal heat exchanger is $100 \%$.

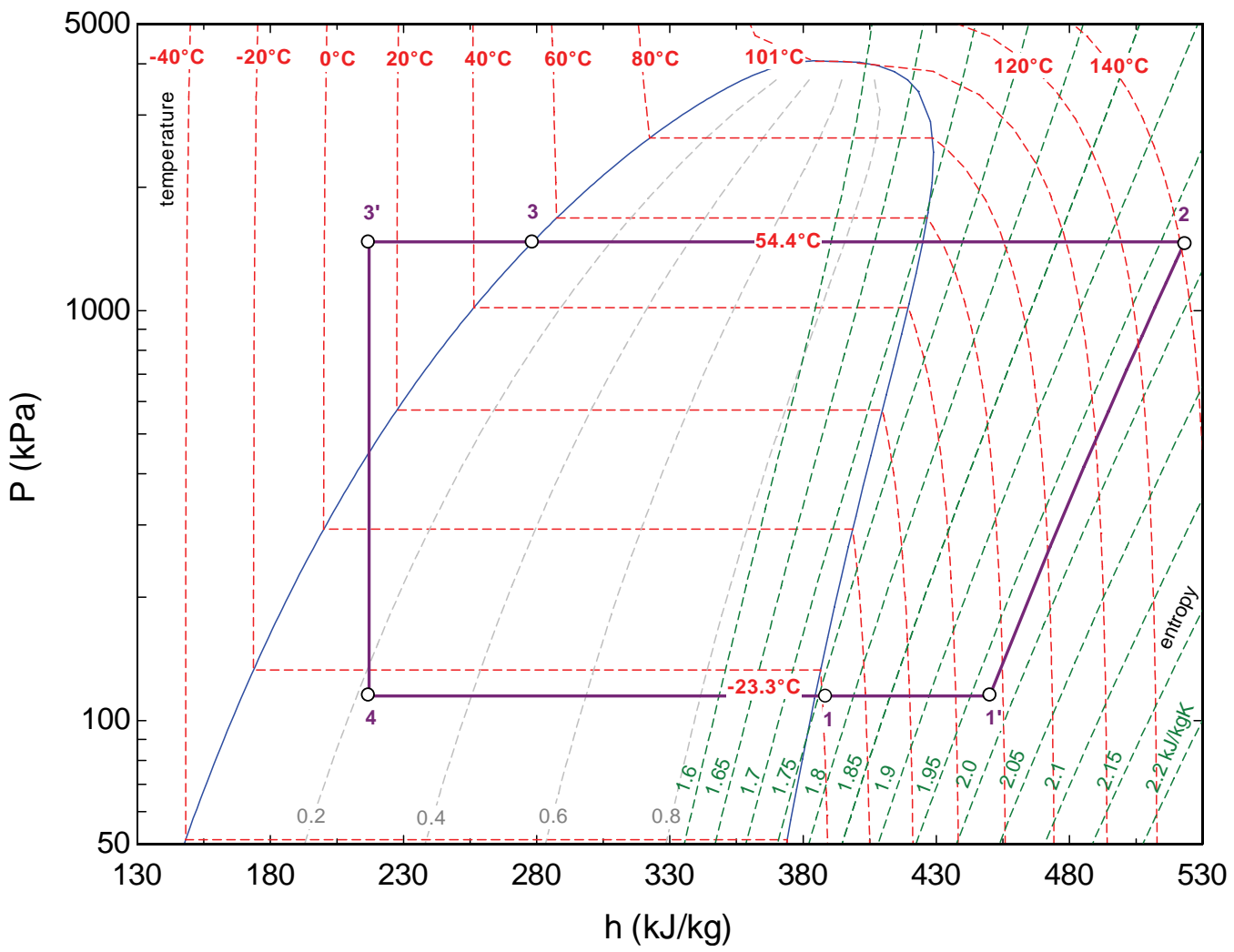

Figure 2. $P$-h diagram of HFC-134a with an idealized vapor compression cycle at the check-point condition. The effectiveness of the internal heat exchanger is $100 \%$. 
Figures 3(a) and 3(b) illustrate the behavior of the specific refrigerating effect and of the volumic refrigerating effect as a function of the evaporating and condensing pressures for HFO-1234yf and HFC-134a, respectively. The effectiveness of the internal heat exchanger was set equal to the typical value of 0.7 in all cases.
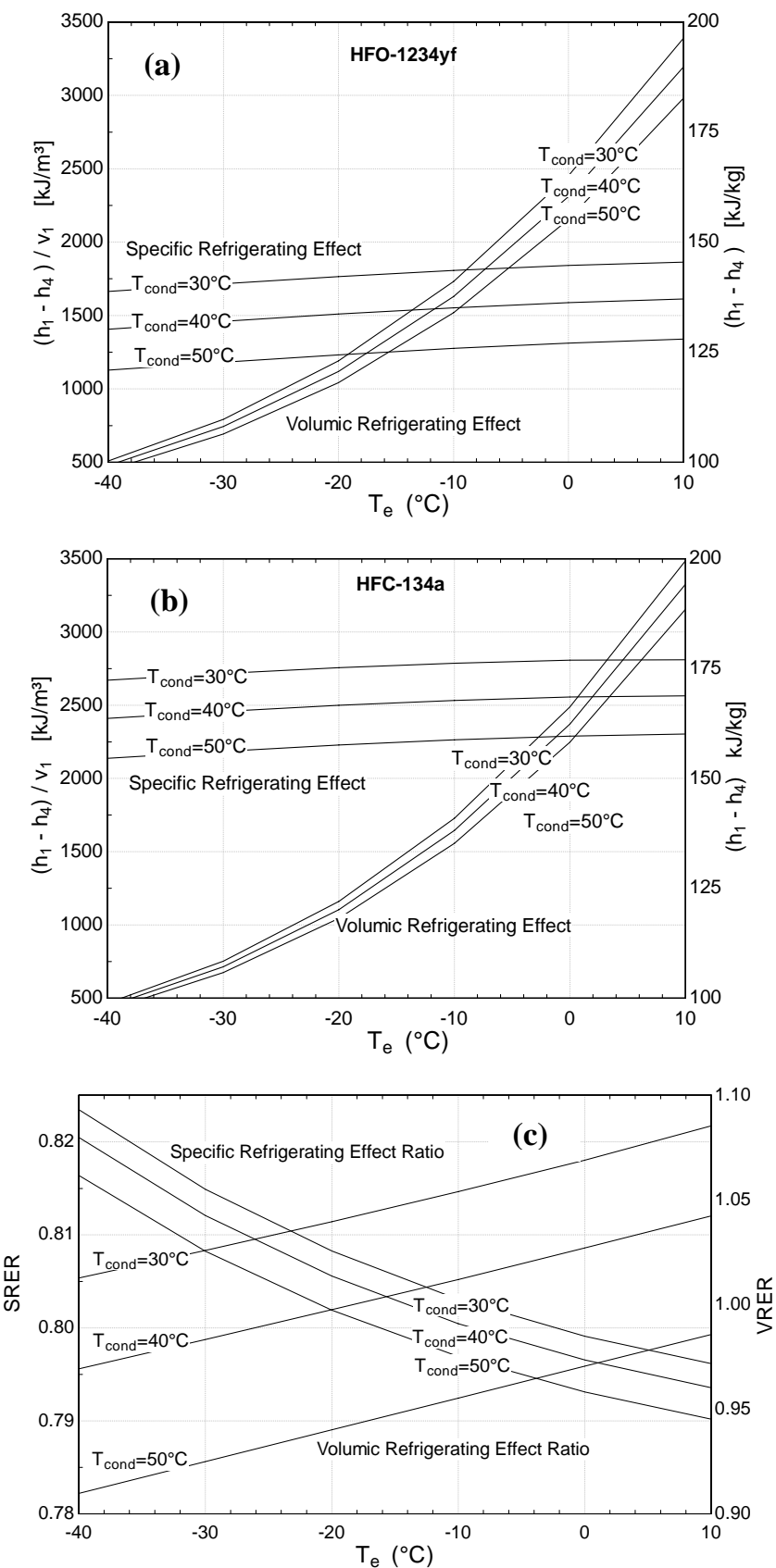

Figure 3. The specific refrigerating effect and volumic refrigerating effect for (a) HFO-1234yf and (b) HFC-134a as a function of evaporating and condensing temperatures. (c) Specific refrigerating effect and volumic refrigerating effect ratios.

For both quantities, HFC-134a exhibits higher values than HFO1234yf, as can be observed in Fig. 3(c) which presents the ratio of the above mentioned quantities for HFO-1234yf to HFC-134a. As pointed out by Gosney (1982), the specific refrigerating effect establishes the mass flow rate of refrigerant necessary to produce a given refrigeration capacity. Thus, the larger the specific refrigerating effect, the smaller the required mass flow rate.
Alternatively, the volumic refrigerating effect establishes the swept volume rate to be achieved with a positive displacement compressor in order to provide a certain refrigeration capacity. A large volumic refrigerating effect can thus be associated with a more compact pump.

Figures 4(a) and 4(b) show the specific work of isentropic compression and volumic work of isentropic compression as a function of the evaporating and condensing pressures for HFO1234yf and HFC134a, respectively. The ratio of both quantities as a function of the same parameters is shown in Fig. 4(c). Again, the internal heat exchanger effectiveness is set equal to 0.7 .
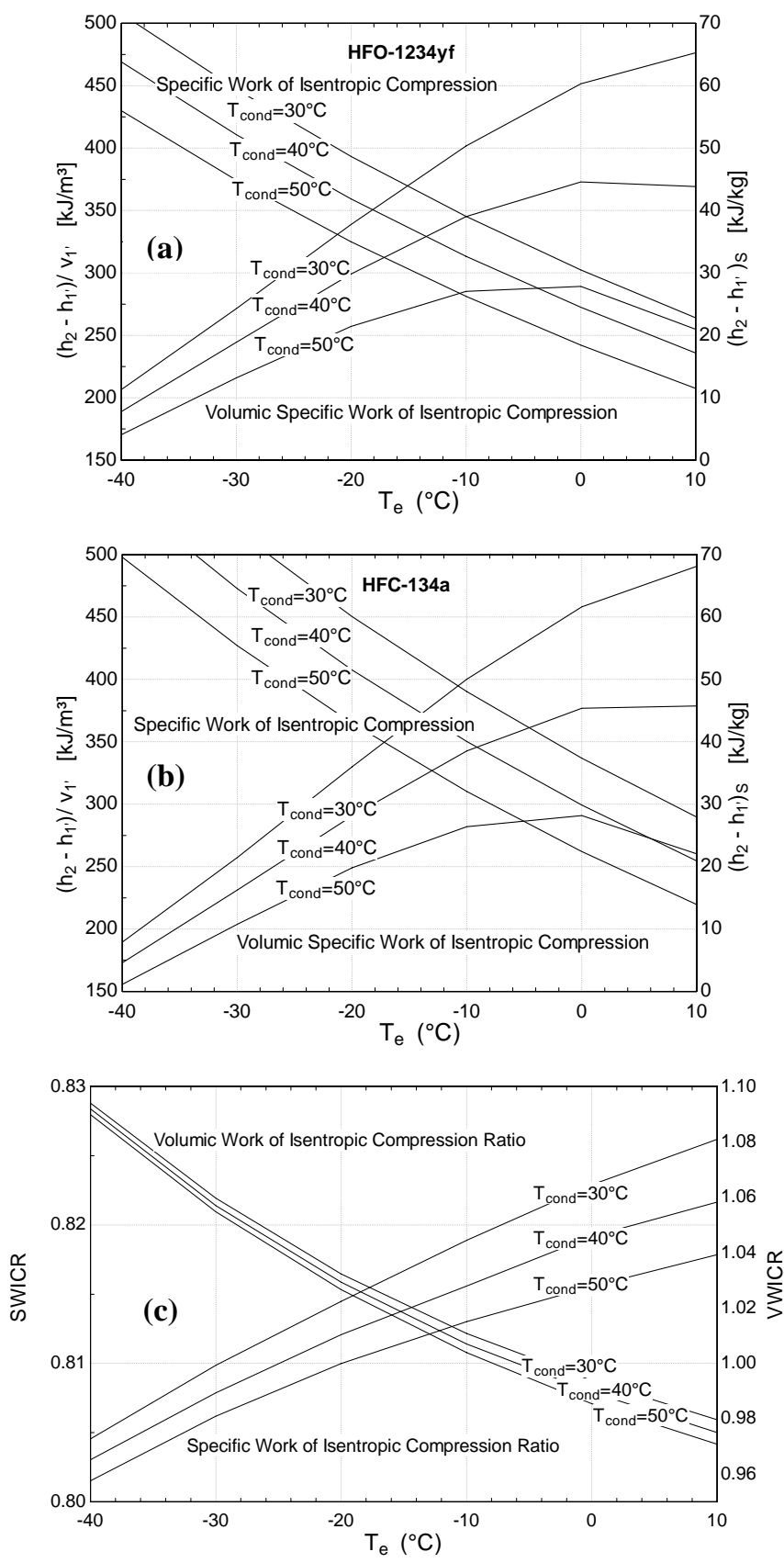

Figure 4. The specific work of isentropic compression and volumic work of isentropic compression for (a) HFO-1234yf and (b) HFC-134a as a function of evaporating and condensing temperatures. (c) Specific work of isentropic compression and volumic work of isentropic compression ratios.

As expected, the specific work of isentropic compression decreases with evaporating temperature and increases with 
condensing temperature for both refrigerants. This quantity is larger for HFC-134a because the increase in $\partial p /\left.\partial h\right|_{s}$ with increasing evaporating temperature is sharper for HFO-1234yf (see Figs. 1 and 2). As a result, the compressor discharge temperature will be lower for HFO-1234yf, as can be seen from Fig. 5. In fact, the values of $\partial p /\left.\partial h\right|_{s}$ for HFO-1234yf are such that in the limiting case of an isentropic compression of an initially saturated vapor, the discharged refrigerant can exit the compressor as a two-phase mixture at the condensing pressure, as can be seen in Fig. 1. The volumic work of isentropic compression represents the mean effective pressure acting on the piston of an ideal positive displacement pump and is, therefore, related to the power which is required to drive the compressor. For both refrigerants, the trends are quite similar, but HFO-1234yf exhibits larger values of this quantity at low evaporating temperatures and slightly smaller values at high evaporating temperatures.

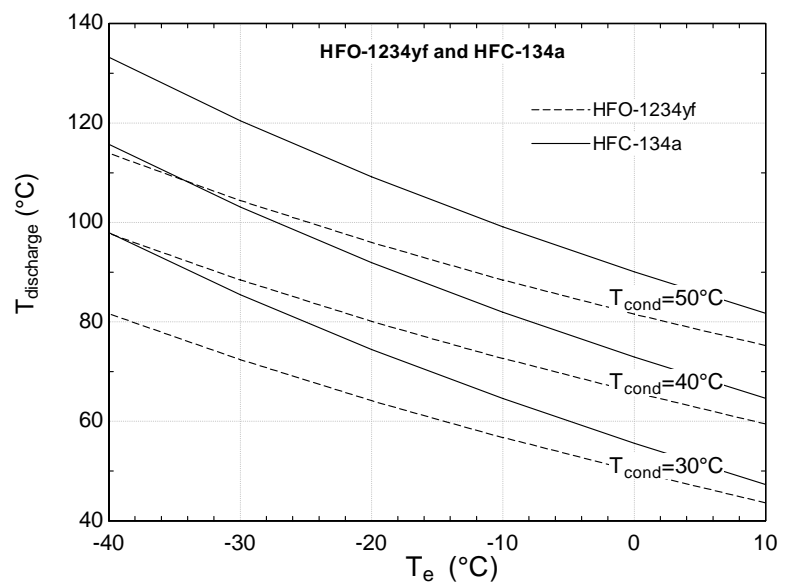

Figure 5. Compressor discharge temperature for HFO-1234yf and HFC$134 \mathrm{a}$ as a function of evaporating and condensing temperatures.

The behavior of the isentropic coefficient of performance (COP) is presented in Fig. 6. Again, the internal heat exchanger effectiveness is set equal to 0.7. As can be seen, HFC-134a exhibits a little but consistently higher values of COP, with a slight increasing difference between the curves with increasing condensing temperature. This is due to the higher values of specific refrigerating effect observed for HFC-134a which clearly prevails over the comparatively lower values of the specific work of isentropic compression associated with HFO-1234yf.

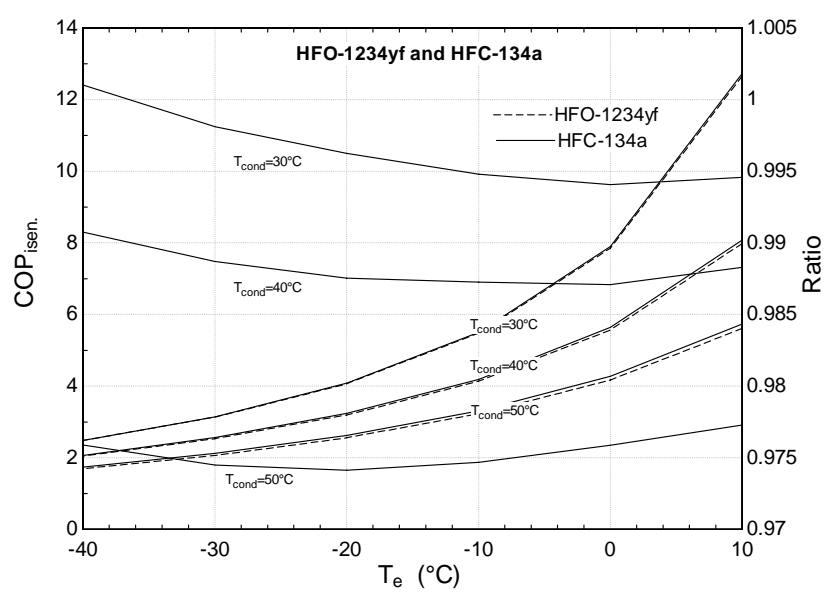

Figure 6. The isentropic coefficient of performance (COP) for HFO-1234y and HFC-134a as a function of evaporating and condensing temperatures.
The influence of the heat exchanger effectiveness on the COP is illustrated in Fig. 7, where the COP has been normalized with respect to the COP at zero effectiveness (i.e. with a $5^{\circ} \mathrm{C}$ superheat at the compressor inlet). The condensing temperature in Fig. 7 has been kept fixed at $50^{\circ} \mathrm{C}$. The presence of an internal heat exchanger is beneficial for both refrigerants in the sense that the COP ratio is greater than unity for any value of effectiveness. This means that the effect of the increase in $h_{1}-h_{4}$ due to the lower refrigerant quality entering the evaporator surmounts that of the increase in $\left(h_{2}-h_{1},\right)_{s}$ associated with the decrease in $\partial p /\left.\partial h\right|_{s}$ with decreasing evaporating pressure. Because $\partial p /\left.\partial h\right|_{s}$ is larger for HFO-1234yf the increase in $\left(h_{2}-h_{1}\right)_{s}$ with increasing compressor inlet temperature is less pronounced than that of HFC-134a, which makes the COP of the new refrigerant larger than that of HFC-134a.

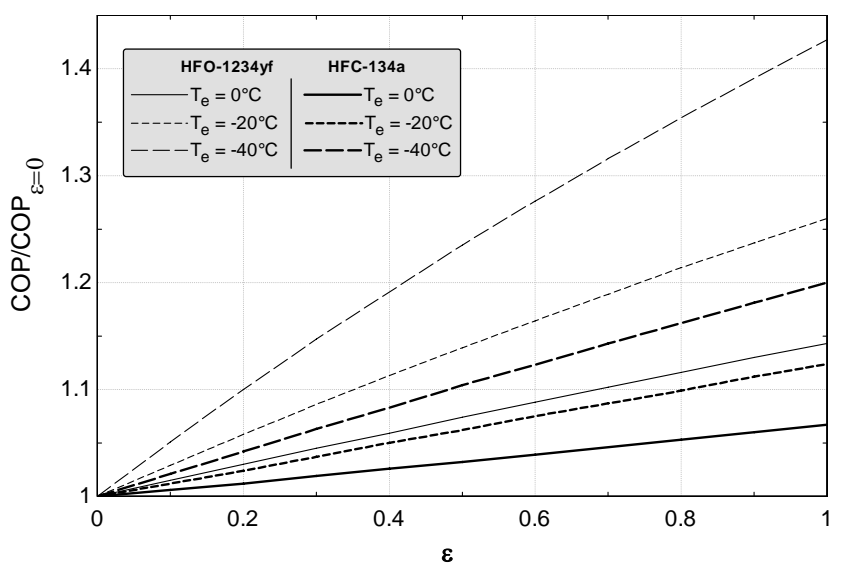

Figure 7. Effect of the heat exchanger effectiveness on the COP. The condensing temperature is equal to $50^{\circ} \mathrm{C}$.

\section{Conclusions}

State and thermodynamic cycle property data were presented for the new refrigerant HFO-1234yf. A calculation approach based on the concept of departure functions employing the Peng and Robinson (1976) equation of state has been employed in order to determine the physical properties of the new refrigerant. The calculation procedure was validated via comparison with existing results and experimental data for HFO-1234yf and HFC-134a.

As far as the cycle properties are concerned, the following conclusions can be drawn:

1. The specific refrigeration effect and the volumic refrigeration effect are both higher for HFC-134a, which means that less mass flow per unit time is needed for a specified refrigeration capacity and thus HFO-1234yf would require a larger swept volume for a specific mass flow rate.

2. The specific work of isentropic compression is larger for HFC-134a due to its more pronounced decrease in $\partial p /\left.\partial h\right|_{s}$ with decreasing evaporating pressure. As a result, the compressor discharge temperature becomes lower for HFO-1234yf, which seems to indicate, together with the larger mass flow rate needed for a specified refrigeration capacity, that careful attention should be paid to the compressor valve design in order to minimize the valve losses.

3. Values of COP for both refrigerants are of the same order of magnitude, the main difference being the response of the COP to a change in the effectiveness of the internal heat exchanger. The increase in COP with increasing effectiveness is more pronounced for HFO-1234yf because $\partial p /\left.\partial h\right|_{s}$ is larger for this refrigerant. 


\section{Acknowledgements}

The authors would like to thank CNPq (Grant No. 573581/2008-8 - National Institute of Science and Technology in Refrigeration and Thermophysics) for the financial support.

\section{References}

Brasz, J.J., 2009, "Variable-speed centrifugal compressor behavior with low GWP refrigerants". In: Proceedings of the International Conference on Compressors and their Systems, Institution of Mechanical Engineers, pp. 247-256, London, UK, September 7-9.

Brown, J.S., Zilio, C., Cavallini, A., 2010 "Thermodynamic properties of eight fluorinated olefins”, International Journal of Refrigeration, Vol. 33, pp. 235-241.

Elliot, J.R., Lira, C.T., 1999, “Introductory Chemical Engineering Thermodynamics”, Prentice Hall, Upper Saddle River, NJ, 660 p.

Gosney, W.B., 1982, "Principles of Refrigeration. Cambridge University Press”, New York, NY, 666 p.

Hankinson, R.W., Thomson, G.H., 1979, “A new correlation for saturated densities of liquids and their mixtures”, AIChE Journal, Vol. 28, pp. 653-663.

Hulse, R., Singh, R., Pham, H., 2009, "Physical properties of HFO1234yf”. In: 3rd IIR Conference on Thermophysical Properties and Transfer Processes of Refrigerants, Paper No. IIR-178, Boulder, CO, June 23-26.

Klein, S.A., 2010, Engineering equation solver (EES), Professional version V8.528.

Leck, T.J., 2009, "Evaluation of HFO-1234yf as a potential replacement for R-134a in refrigeration applications". In: 3rd IIR Conference on Thermophysical Properties and Transfer Processes of Refrigerants, Paper No. IIR-155, Boulder, CO, June 23-26.

Lemmon, E.W., Huber, M.L., McLinden, M.O., 2007, “REFPROP Reference Fluid Thermodynamic and Transport Properties”, NIST Standard Reference Database 23, Version 8.0, National Institute of Science and Technology, Boulder, CO, USA.

Minor, B., Spatz, M., 2008, "HFO-1234yf low GWP refrigerant update”. In: International Refrigeration and Air Conditioning Conference at Purdue, Paper No. 2349, West Lafayette, IN, July 14-17.

Peng, D.Y., Robinson, D.B., 1976, “A new two-constant equation of state”. Industrial and Engineering Chemistry: Fundamentals, Vol. 15, pp. 59-64.

Poling, B.E., Prausnitz, J.M., O’Connell, J.P., 2000, “The properties of gases and liquids”. Fifth Edition, McGraw-Hill, NY, 681 p.

Stoecker, W.F., Jones, J.W., 1982, “Refrigeration and air conditioning”. Second Edition, McGraw-Hill, New York, NY, 443 p.

Tanaka, K., Higashi, Y., 2009, "Thermodynamic properties of HFO1234yf (2,3,3,3-tetrafluoropropene)”. In: 3rd IIR Conference on Thermophysical Properties and Transfer Processes of Refrigerants, Paper No. IIR-136, Boulder, CO, June 23-26.
Tillner-Roth, R., Baehr, H.D., 1994, “An international standard formulation of the thermodynamic properties of 1,1,1,2-tetrafluoroethane (HFC-134a) for temperatures from $170 \mathrm{~K}$ to $455 \mathrm{~K}$ at pressures up to 70 MPa”, The Journal of Physical Chemistry, Vol. 23, pp. 657-729.

\section{Appendix}

The HFO-1234yf molecular parameters and experimental data fits of vapor pressure, saturated liquid density and ideal gas heat capacity at constant pressure provided by Leck (2009) are summarized below. Table A.1 presents the molar mass, critical temperature and pressure and acentric factor of HFO-1234yf. The vapor pressure relationships are given by (Leck, 2009):

$\ln P_{\text {sat }}=A+\frac{B}{T}+C \ln T+D T+E\left(\frac{F-T}{T}\right) \ln (F-T)$

$\frac{1}{P} \frac{d P_{s a t}}{d T}=-\frac{B}{T^{2}}+\frac{C}{T}+D-E\left[\frac{F}{T^{2}} \ln (F-T)+\frac{1}{T}\right]$

where $P$ is in $\mathrm{kPa}$ and $T$ is in $\mathrm{K}$. The constants are presented in Table A.2.

The saturated liquid mass density correlation is given by (Leck, 2009):

$\frac{\rho_{f}}{478.0}=\sum_{i=0}^{4} d_{i} X^{i}$

$X=\left(1-\frac{T}{367.85}\right)^{\frac{1}{3}}-0.3315471$

where $\rho_{f}$ is in $\mathrm{k} \mathrm{gm}^{-3}$ and $T$ is in $\mathrm{K}$. The constants are presented in Table A.3.

The ideal gas specific heat capacity correlation is given by (Leck, 2009):

$c_{P}^{i g}=\sum_{i=0}^{5} c_{i} T^{i}$

where $c_{P}^{i g}$ is in $\mathrm{kJ} \mathrm{kg}^{-1} \mathrm{~K}^{-1}$ and $T$ is in $\mathrm{K}$. The constants are presented in Table A.4.

Table A.1. HFO-1234yf properties.

\begin{tabular}{cccc}
\hline$M\left(\mathrm{~kg} \mathrm{kmol}^{-1}\right)$ & $T_{c}(\mathrm{~K})$ & $P_{c}(\mathrm{kPa})$ & $\omega$ \\
\hline 114.04 & 367.85 & 3374.87 & 0.27803 \\
\hline
\end{tabular}

Table A.2. Constants for Eqs. (A.1) and (A.2).

\begin{tabular}{cccccc}
\hline$A$ & $B$ & $C$ & $D$ & $E$ & $F$ \\
\hline 48.70134 & -4054.888 & -5.353373 & $5.632772 \times 10^{-3}$ & 0.2423738 & 368.7851 \\
\hline
\end{tabular}

Table A.3. Constants for Eqs. (A.3) and (A.4).

\begin{tabular}{ccccc}
\hline$d_{0}$ & $d_{1}$ & $d_{2}$ & $d_{3}$ & $d_{4}$ \\
\hline 1.667131 & 2.314933 & 1.032059 & 0.09413147 & -0.8200684 \\
\hline
\end{tabular}

Table A.4. Constants for Eq. (A.5).

\begin{tabular}{ccccc}
\hline$c_{0}$ & $c_{1}$ & $c_{2}$ & $c_{3}$ & $c_{5}$ \\
\hline 0.233399 & $1.82451 \times 10^{-3}$ & $3.51596 \times 10^{-6}$ & $-1.12489 \times 10^{-8}$ & $1.06071 \times 10^{-11}$ \\
\hline
\end{tabular}

